\title{
Health-related quality of life in children and adolescents after systemic sting reaction
}

\author{
Piotr Brzyski ${ }^{1, A, C-D, F}$, Ewa Cichocka-Jarosz ${ }^{2, A-F}$, Izabella Tarczoń2,B,E-F, \\ Urszula Jedynak-Wąsowicz ${ }^{2, B, E-F}$, Tomasz Tomasik ${ }^{2, B, F}$, Grzegorz Lis ${ }^{2, F}$ \\ ${ }^{1}$ DZIUPLA Statistical analysis, Krakow, Poland \\ 2 Department of Paediatrics, Jagiellonian University Medical College, Krakow, Poland \\ A - Research concept and design, B - Collection and/or assembly of data, C - Data analysis and interpretation, \\ $D$ - Writing the article, E - Critical revision of the article, F - Final approval of article
}

Brzyski P, Cichocka-Jarosz E, Tarczoń I, Jedynak-Wąsowicz U, Tomasik T, Lis G. Health-related quality of life in children and adolescents after systemic sting reaction. Ann Agric Environ Med. 2019; 26(1): 103-108. doi: 10.26444/aaem/93747

\begin{abstract}
Introduction and objectives. Insect stings are the second trigger of anaphylaxis in children and adolescents, causing a potentially life-threatening reactions. Hence health-related quality of life (HRQoL) is an important issue for Hymenoptera venom allergy (HVA) patients. The aim of this cross-sectional study was to evaluate the impact of HVA on young patients' HRQoL, including their socio-demographic characteristics.

Materials and method. The study sample included 102 patients aged 8-17 (Mean 12.5 years, SD=3.0), who were under diagnosis or venom immunotherapy due to systemic reaction after an insect sting in one of the tertiary referential centers in Poland. They were mostly boys (70\%), and mainly from rural areas (63\%). HRQoL of studied patients was measured with the Children's Hymenoptera Venom Allergy Quality of Life Scale, a questionnaire covering 6 dimensions: anxiety, caution, limitations, discomfort, support received from parents and a feeling of safety, each measured from 1 to 5 . Independent predictors of HRQoL were estimated using the Generalized Linear Model.

Results. In the group of children being dermal reactors, girls reported a higher level of anxiety $(B=1.17,95 \% C l=(0.30 ; 2.03)$, $\mathrm{p}=0.008)$. In the group of children with grade 2 it was the girls who reported lower anxiety $(B=-1.33,95 \% C l=(-2.38 ;-0.29)$, $p=0.013)$. Boys treated longer than 3 years had their level of anxiety significantly lower than those studied at diagnosis $(B=-0.65,95 \% \mathrm{Cl}=(-1.23 ;-0.07), \mathrm{p}=0.028)$. The feeling of safety was higher in children living in villages than in those living in towns $(B=0.30,95 \% \mathrm{Cl}=(0.03 ; 0.56), \mathrm{p}=0.031)$.

Conclusions. The gender, treatment duration and stage of anaphylactic reaction influenced level of anxiety. The level of feeling of safety was related to the place of living.
\end{abstract}

\section{Key words}

health-related quality of life, children, adolescents, insect sting, Hymenoptera venom allergy, cross-sectional study

\section{INTRODUCTION}

Health-related quality of life (HRQoL) has recently emerged as an important concept and outcome in clinical practice and health care. The concept of HRQoL measurement is based on a subjective evaluation of how significantly the health condition influences a patient's everyday life. It is usually conducted in several dimensions [1]. Insect stings are second among risk factors of anaphylaxis in children [2]. Severity of systemic allergic reactions to Hymenoptera venom $(\mathrm{HV})$ is categorized into 4 grades in Mueller's classification, from the mildest reaction to potentially fatal, with leading symptoms as follows: $1^{\text {st }}-$ dermal, $2^{\text {nd }}-$ gastrointestinal, $3^{\text {rd }}$ - respiratory, and $4^{\text {th }}$ - anaphylactic shock $[3,4]$. Similarly to other allergic [5-9] and non-allergic diseases [10], the influence of Hymenoptera venom allergy (HVA) on HRQoL is obvious and of great importance.

One of the main goals of venom immunotherapy (VIT), is desensitization to Hymenoptera venom, and thereby improvement of HRQoL of the sensitized persons [11]. Until the development of the Children's Hymenoptera Venom Allergy Quality of Life Scale (CHVAQoLS), the first

Address for correspondence: Ewa Cichocka-Jarosz, Jagiellonian University Medical College, Department of Pediatrics, Krakow, Poland

e-mail: mijarosz@cyfronet.pl

Received: 30.03.2018; accepted: 24.07.2018; first published: 19.09.2018 measurement tool designed for assessment of HRQoL of both children and adolescents with HVA, the results of studies on HRQoL in these groups were not comparable [4, 12-14].

\section{OBJECTIVES}

The aim of this cross-sectional study was to: evaluate the impact of HVA on children's and adolescents' HRQoL to assess interrelationship between particular dimensions of their HRQoL (Fig. 1), and to identify the independent predictors related to the particular HRQoL dimensions, taking into account the impact of socio-demographic and clinical characteristics.

\section{MATERIALS AND METHOD}

Study sample. The study sample included 102 children aged 8-17 (mean age 12.5 years, $\mathrm{SD}=3.0$ ) who, due to systemic reaction (SR) after an insect sting (IS) were under diagnosis or within the course of allergen immunotherapy at the Department of Pulmonology, Alergology and Dermatology, University Children' Hospital in Krakow, Poland in 20102013. They were mostly boys (70\%), from rural areas (63\%). Written consent was obtained from the children and their 


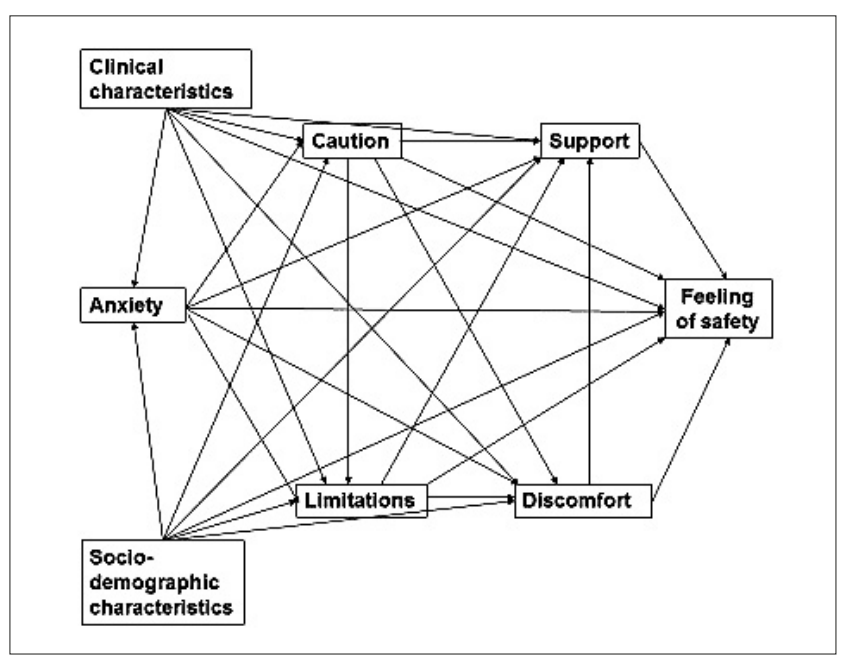

Figure 1. Model of the hypothesized relationships between dimensions of $\mathrm{HRQOL}$ of children and adolescents with HVA

parents. The Bioethical Committee of the Jagiellonian University approved the study.

Measures. HRQoL of children and adolescents with HVA was measured with the CHVAQoLS, a self-administered questionnaire consisting of 19 items and covering 6 dimensions: 1) anxiety, 2) caution, 3) limitations, 4) discomfort, 5) support received from parents and 6) feeling of safety. Each dimension was measured with 3 items (except safety with 4 items), on a scale ranging from 1 to 5 . Reliability of the subscales was estimated by the authors of the scale as: 0.83 for anxiety and for caution, 0.82 - limitations, 0.83 - discomfort, 0.79 - support, and 0.72 for feeling of safety $[4,12])$. The reliability of the scale in the studied sample was established as: $0.81,0.80,0.86,0.86,0.81,0.80$ for respective subscales. In the sample under study, factor analysis revealed 4 factor structures of the scale: the first factor was defined by items from limitations and discomfort subscales, whereas the second was defined by items from caution and anxiety subscales. The third factor was defined by items from the safety subscale, and the fourth factor was defined by items from the support subscale. The questionnaire was filled-in during a visit to the centre, after diagnostic or immunotherapy procedures.

In the regression models, the gender of the child and its place of residence were analyzed as binary variables, while male gender and urban background were treated as reference categories for respective variables. Age was considered as a continuous variable, and because it interacted in particular models with other variables, it was centered around the value of 10 .

The severity of a systemic reaction was coded as 1-4, according to the grades of Mueller's classification [3]. Because of a small percentage of children with a large local reaction (LLR, exclusively in the region of face and neck) in the sample, this category was aggregated with children with Mueller's $1^{\text {st }}$ grade (so-called dermal reactors), which was regarded as a reference grade in regression models.

The children were divided into the following 4 categories, those who were studied: 1 ) at diagnosis (treated as a reference group); 2) at the beginning of an incremental dose of VIT; 3 ) within up to 3 years of the maintenance dose and, finally, 4) those treated over a period longer than 3 years of the maintenance dose. The period census was selected owing to 2 reasons: it is the shortest period after which VIT may be stopped and, additionally, in the case of the sample in this study, it provided similar sizes of these 2 categories.

The children under treatment completed the questionnaire between September - October, whereas those diagnosed or just starting treatment usually answered the questionnaire out of the period of insect activity. The time between April - October is regarded as the high season of Hymenoptera's activity, referred to as 'the season' in this study, therefore a binary variable was introduced as a confounder in the regression models, indicating those studied out of the season.

The children were classified as bee-stung, wasp-stung, or those who had been stung by an unidentified insect, the last category concerning only those children who answered the questionnaire at the diagnosis stage (treated as a reference category).

Statistical analysis. Qualitative variables were described as counts (n) and percentages (\%), while quantitative variables were described as means and standard deviations.

Factor analysis using the principal component method with Varimax rotation was used to investigate factor structure of the items constituting CHVAQoLS, and the Cronbach alpha coefficient was used to estimate reliability of the scale.

Linear regression models were estimated by means of Generalized Linear Model (GZLM), with identity linking function and variables of normal distribution as dependent ones. Regression results were presented as raw regression coefficients B, and 95\% confidence intervals (95\%CI) and respective $\mathrm{p}$ values. All 2-way interactions between variables in the model were tested. In cases of some significant interactions, the model was estimated separately for groups specified by one of the variables involved in the interaction.

Some variables represented nested effects of LLRs and Mueller's $1^{\text {st }}$ grade or unidentified culprit insect, both observed only in children studied at diagnosis. In case of these variables separation of the effects was not possible; so they were tested in separate models and the most significant of them was included in the final model.

Effects with $\mathrm{p}<0.05$ were treated as statistically significant. IBM SPSS Statistics 21 for Windows software was used.

\section{RESULTS}

Clinical characteristics. There was a predominance of $2^{\text {nd }}$ and $3^{\text {rd }}$ grade of SR in Mueller's classification. HRQoL measurement was mostly made at the diagnosis of a suspected HVA child, whereas children studied at different stages of VIT constituted subgroups of similar size. All children who were studied after diagnosis identified the culprit insect as a bee or a wasp, whereas for $50 \%$ of the children who answered the questionnaire at the stage of diagnosis, (it concerned 20\% of entire sample), the type of insect was unidentified. With $47 \%$ of the children, the survey was performed out of the season (Tab. 1).

Health-related Quality of Life characteristics given by children and adolescents. According to the classification of quality of life level proposed by the authors (1-1.79 - very low, 1.8-2.59 - low, 2.6-3.4 - moderate, 3.41-4.2 - high, 4.21-5.0 - very high) [15], children reported moderate levels 
Table 1. Clinical characteristics of study group

\begin{tabular}{lcc}
\hline & $\mathrm{N}$ & $\%$ \\
\hline Stage of treatment & & \\
\hline Diagnosis & 41 & 40.2 \\
\hline VIT beginning & 19 & 18.6 \\
\hline Up to 3 years of VIT & 22 & 21.6 \\
\hline 3 years of VIT or longer & 20 & 19.6 \\
\hline Culprit insect & & \\
\hline Unidentified & 20 & 19.5 \\
\hline Wasp $^{\text {M }}$ & 39 & 38.3 \\
\hline Honey bee & 43 & 42.2 \\
\hline Mueller's grade of anaphylactic reaction before diagnosis & & \\
\hline${\text { LLR or } 1^{\text {st }}}^{\text {nd }}$ & 15 & 14.7 \\
\hline $2^{\text {rd }}$ & 32 & 31.4 \\
\hline $4^{\text {th }}$ & 30 & 29.4 \\
\hline Total & 25 & 24.5 \\
\hline
\end{tabular}

of anxiety, received support and feeling of safety. In contrast, their levels of limitations and discomfort were low, while their caution level was high (Tab. 2).

Table 2. Mean levels of dimensions of HRQoL in HVA children and adolescents studied

\begin{tabular}{lccc}
\hline Dimension & mean & SD & No. of items \\
\hline Anxiety & 2.7 & 0.9 & 3 \\
\hline Caution & 3.7 & 0.9 & 3 \\
\hline Limitations & 2.3 & 0.9 & 3 \\
\hline Discomfort & 2.5 & 1.0 & 3 \\
\hline Support received & 2.8 & 1.0 & 3 \\
\hline Feeling of safety & 2.6 & 0.8 & 4 \\
\hline
\end{tabular}

Multivariate analysis. A regression model, including the severity of anaphylactic reaction and the gender, showed that in the group of children with LLR or $1^{\text {st }}$ grade of anaphylactic reactions, the girls reported a higher level of anxiety than the boys $(\mathrm{B}=1.17,95 \% \mathrm{CI}=(0.30 ; 2.03) ; \mathrm{p}=0.008)$, whereas in the group of children with higher grades it was the girls who reported lower anxiety; however, it was only among those with $2^{\text {nd }}$ grade that the difference was significant $(B=-1.33$,
$95 \% \mathrm{CI}=(-2.38 ;-0.29) ; \mathrm{p}=0.013)$. The other regression results for anxiety were presented separately for the boys and the girls.

The boys with $2^{\text {nd }}$ grade of anaphylactic reaction had significantly higher anxiety than those who were dermal reactors only. Boys treated for more than 3 years had an anxiety level significantly lower than those studied at diagnosis. Significant interaction between the age and the time of HRQoL assessment indicated that girls aged 10 years old, studied out of the season of insect activity, reported higher anxiety than those studied during the season. Interestingly, for the girls studied during the season, anxiety increased along with their age, whereas for the girls studied out of the season, anxiety decreased (Tab. 3).

Caution was significantly higher in girls than in boys $(\mathrm{B}=0.35,95 \% \mathrm{CI}=(0.07 ; 0.64): \mathrm{p}=0.015)$ as well as in children with $4^{\text {th }}(B=0.61,95 \% \mathrm{CI}=(0.14 ; 1.07) ; \mathrm{p}=0.010)$ or $2^{\text {nd }}(\mathrm{B}=0.55$, $95 \% \mathrm{CI}=(0.10 ; 1.00) ; \mathrm{p}=0.018)$ Mueller's grade of anaphylactic reaction, in comparison to dermal reactors. Caution was lower in children treated for more than 3 years than in those who were studied at diagnosis $(\mathrm{B}=-0.41,95 \% \mathrm{CI}=(-0.82 ;-0.01)$; $\mathrm{p}=0.046)$, and this increased along with increasing anxiety $(\mathrm{B}=0.51,95 \% \mathrm{CI}=(0.37 ; 0.66) ; \mathrm{p}<0.001)$.

A significant interaction between the place of residence and the type of culprit insect indicated that for the children living in towns, limitations were higher among those who, beyond doubt, had been stung by wasps, compared with the children stung by an unidentified insect. For children stung by unidentified insects, limitations were higher among those living in villages, while the difference in limitations level between village dwelling children stung by wasp and by unidentified insect was significantly smaller than the difference between town dwelling children stung by wasp and by unidentified insect, resulting in actually the same level of limitations in wasp stung children, irrespective of place of residence. Limitation levels increased along with the children's increasing anxiety (Tab. 4).

A significant interaction between age and Mueller's grade of anaphylactic reaction indicated that in children who were dermal reactors only, discomfort decreased along with age, while in children with no less than the $2^{\text {nd }}$ grade it increased; the difference between the slopes of these relationships was statistically significant $(B=0.20,95 \% C I=(0.06 ; 0.35)$; $\mathrm{p}=0.006)$. Discomfort increased along with growing anxiety $(\mathrm{B}=0.25,95 \% \mathrm{CI}=(0.07 ; 0.42) ; \mathrm{p}=0.007)$ and caution $(\mathrm{B}=0.22$, $95 \% \mathrm{CI}=(0.06 ; 0.39) ; \mathrm{p}=0.011)$, as well as with increasing limitations $(B=0.61,95 \% C I=(0.46 ; 0.77), p<0.001)$.

Table 3. Independent predictors of anxiety in HVA children with respect to their gender

\begin{tabular}{|c|c|c|c|c|c|c|c|c|}
\hline & \multicolumn{4}{|c|}{ Boys } & \multicolumn{4}{|c|}{ Girls } \\
\hline & B & $95 \% \mathrm{Cl}$ & & $\mathrm{p}$ & B & $95 \% \mathrm{Cl}$ & & $\mathrm{p}$ \\
\hline Age & 0.02 & -0.09 & 0.12 & 0.776 & 0.13 & 0.01 & 0.25 & 0.044 \\
\hline Being studied out of season of insect's activity & 0.28 & -0.30 & 0.85 & 0.344 & 0.71 & -0.02 & 1.44 & 0.057 \\
\hline Interaction between being studied out of season and age & -0.07 & -0.20 & 0.07 & 0.353 & -0.25 & -0.45 & -0.05 & 0.016 \\
\hline Stage: VIT beginning vs. Diagnosis & -0.05 & -0.66 & 0.57 & 0.887 & 0.04 & -0.79 & 0.88 & 0.918 \\
\hline Stage: 3 years of VIT or longer vs. Diagnosis & -0.65 & -1.23 & -0.07 & 0.028 & -0.51 & -1.52 & 0.50 & 0.322 \\
\hline Mueller's grade: $2^{\text {nd }}$ vs. $1^{\text {st }}$ or LLR & 0.66 & -0.04 & 1.35 & 0.064 & -0.64 & -1.59 & 0.30 & 0.182 \\
\hline Mueller's grade: $3^{\text {rd }}$ vs. $1^{\text {st }}$ or LLR & 0.54 & -0.15 & 1.23 & 0.125 & -0.40 & -1.37 & 0.56 & 0.416 \\
\hline Mueller's grade: $4^{\text {th }}$ vs. $1^{\text {st }}$ or LLR & 0.42 & -0.27 & 1.11 & 0.228 & -0.28 & -1.23 & 0.67 & 0.565 \\
\hline Constant & 2.25 & 1.63 & 2.88 & 0.000 & 3.18 & 2.40 & 3.96 & $<0.001$ \\
\hline
\end{tabular}


Table 4. Independent predictors of level of limitations in HVA children

\begin{tabular}{lcccc}
\hline & B & \multicolumn{3}{c}{ Wald's 95\% Cl } \\
& \multicolumn{5}{c}{ limits } \\
\hline Age & -0.04 & -0.086 & 0.005 & 0.079 \\
\hline Culprit insect: Wasp vs Unidentified & 1.35 & 0.78 & 1.92 & $<0.001$ \\
\hline Culprit insect: Honey bee vs Unidentified & 0.43 & -0.13 & 1.00 & 0.129 \\
\hline Place of residence: village vs town (ref.) & 1.07 & 0.47 & 1.67 & $<0.001$ \\
\hline Interaction between culprit insect and place of living & & & \\
\hline \multicolumn{1}{c}{ Wasp and village } & -1.33 & -2.08 & -0.59 & $<0.001$ \\
\hline Honey bee and village & -0.65 & -1.39 & 0.08 & 0.080 \\
\hline Anxiety & 0.41 & 0.26 & 0.56 & $<0.001$ \\
\hline Constant & $\mathbf{0 . 8 7}$ & $\mathbf{0 . 0 2}$ & $\mathbf{1 . 7 3}$ & $\mathbf{0 . 0 4 6}$
\end{tabular}

Assessment of received support by children from their parents was higher in children with $2^{\text {nd }}(B=0.99$, $95 \% \mathrm{CI}=(0.40 ; 1.57), \mathrm{p}=0.001), 3^{\text {rd }}(\mathrm{B}=1.04,95 \% \mathrm{CI}=(0.47 ; 1.62)$, $\mathrm{p}<0.001)$ and $4^{\text {th }}$ Mueller's grade $(\mathrm{B}=0.87,95 \% \mathrm{CI}=(0.28 ; 1.45)$; $\mathrm{p}=0.004)$, than in dermal reactors. Support received by the children treated for longer than 3 years was significantly lower than received by those studied at diagnosis $(B=-0.77$, $95 \% \mathrm{CI}=(-1.28 ;-0.28) ; \mathrm{p}=0.003)$. Support increased along with child's caution $(B=0.29,95 \% \mathrm{CI}=(0.09 ; 0.49) ; \mathrm{p}=0.006)$ and discomfort $(B=0.27,95 \% C I=(0.08 ; 0.46) ; \mathrm{p}=0.006)$.

The feeling of safety was higher in the children living in villages than in those living in towns $(B=0.30$, $95 \% \mathrm{CI}=(0.03 ; 0.56) ; \mathrm{p}=0.031)$ and it decreased along with increasing anxiety $(\mathrm{B}=-0.51,95 \% \mathrm{CI}=(-0.66 ;-0.36) ; \mathrm{p}<0.001)$.

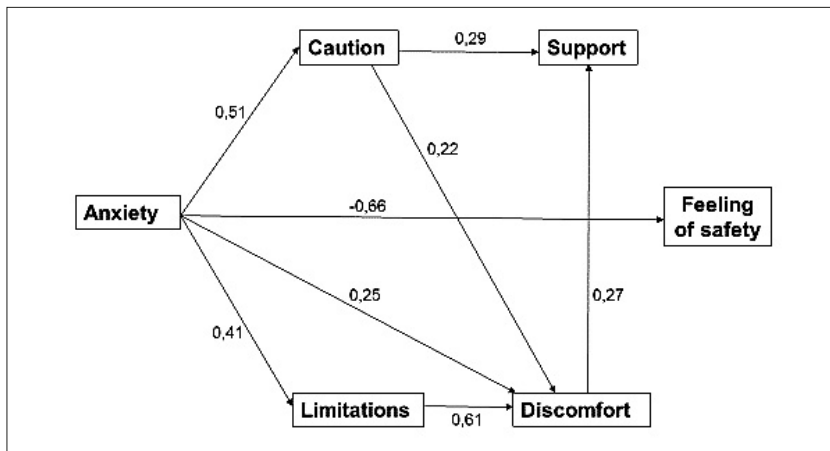

Figure 2. Statistically significant relationships between dimensions of HRQoL of children and adolescents with HVA.

Numbers are unstandardized linear regression coefficients

\section{DISCUSSION}

This paper presents the results of the first study conducted by means of CHVAQoLS, the only scale designed for measuring HRQoL in children and adolescents with HVA. The obtained results show that particular dimensions of children's and adolescents' HRQoL are affected by young patients' clinical and socio-demographic characteristics, as well as are related to other dimensions of HRQoL (Fig. 2). The results obtained in the presented study will be compared with the authors' previous studies conducted separately in children with HVA, aged up to 13 years, and in adolescents with HVA aged 14 and older, using Polish adaptations of VQLQ [16, 17].
Our results show that anxiety (especially with respect to the boys), caution and support were related to the stage of treatment: they were significantly lower in the children treated for more than 3 years than in the children studied at diagnosis. With regard to anxiety, this result may be directly treated as an improvement in HRQoL, whereas in the case of caution and support, it may be indirectly considered in the same way, i.e. as a lessening of some burden related to attempts to avoid a sting (caution), or as a diminished need of parents actions (support helping the child live with a potentially life-threatening health condition). Patients treated with VIT are protected before systemic reaction just after reaching the maintenance dose, but only a longer treatment time or good tolerance of subsequent stings results in improvement of the safety feeling. No such relationships were observed in the authors' previous studies, mainly due to samples restricted only to young patients in the course of on-going or finalised treatment $[16,17]$.

The presented study shows that children with at least $2^{\text {nd }}$ grade of anaphylactic reaction reported higher caution, which may be explained by the fact that it is generally children with that grade who are qualified for VIT. Also, since a higher grade of anaphylactic reaction before treatment reflects a higher life hazard, the qualification itself may be treated as a confirmation that child's life is at risk; therefore, more caution is needed to keep danger at bay. The same reason may lay behind the results which showed that the support received was higher in the same group of children.

The results obtained in the current study indicate that discomfort decreased along with age, a finding which had not been observed in the authors' previous studies. However, those studies were conducted only on samples of children with at least $2^{\text {nd }}$ grade $[16,17]$. Moreover, in this study, the relationship between age and discomfort ran in different directions, which may result from greater awareness related to older age. Among children with milder reactions, these being older, were more aware of lack of danger, hence their discomfort was smaller. Opposite to these being severe reactors, older and more aware children felt greater discomfort. It means that older children with mild reactions are less disturbed by their symptoms, but in the same age group with severe symptoms, experienced greater discomfort.

Some gender-related differences were observed with the girls reporting higher anxiety than the boys. This relationship only existed among the children who were dermal reactors, whereas among the children with at least $2^{\text {nd }}$ grade, this relationship was the opposite. A similar result was obtained based on the data originating from the sample of HVA children treated with VIT, in which the girls reported higher anxiety than the boys, although regardless of the grade of anaphylactic reaction and age [17]. In another previous studies of authors' conducted among adolescents (14-yearold and older) with at least $2^{\text {nd }}$ grade treated with VIT, and those who had completed treatment, it was observed that the level of anxiety was lower in older boys than in girls (irrespective of their age), whereas the girls did not differ in this matter from younger boys [16]. This result is also similar to those coming from psychological studies, which showed that the level of anxiety the trait (defined as an indicator of a tendency to perceive relatively non-threatening situations as more dangerous than they really are), was generally higher in girls than in boys [18]. 
The current study also reveals some relationships which had not been observed in previous studies by the authors, namely that girls are characterized by higher caution than boys, which is an expected result if caution is regarded as an attitude opposite to a tendency to risk taking, the level of which is observed as lower among girls [19].

Level of safety was also reported as higher by the children and adolescents living in villages, which may be slightly surprising, as those patients are at higher risk of being stung, especially by honey bees. Probably standing under supervision of HVA specialist or being under VIT treatment, may improve the feeling of safety in these children.

Moreover, the level of limitations differed between those living in towns and those living in villages in relation to the culprit insect. This may result from the fact that the knowledge of an insect which poses a danger, may strongly impact a range of situations in which a child has to change its behaviour, for instance, when a child lives close to a beehive and is sensitive to wasp venom. To some extent, these results resemble the results the authors' previous study on adolescents, where a significant impact of gender interacting with the place of residence was observed: limitations were the highest in girls and decreased along with the age of boys, yet they were higher in boys living in villages than in those the same age living in towns [16].

The presented study shows that caution increases along with growing anxiety, which is in line with the results of the authors' previous studies conducted both in children and adolescents $[16,17]$. This relationship is a consequence of the fact that caution is a way of coping with anxiety and discomfort caused by HVA.

It seems to be natural that the level of limitations depends on the level of anxiety, whereas the authors' previous study showed that higher limitations in adolescents were related to higher caution, but not to anxiety [16]. This difference may result from limitations of the previously used measurement tool where the limitations were measured with one question only, covering in general the sense of limitations due to HVA, and the fact that previous studies had been conducted separately among children and adolescents $[13,14]$.

A significant influence of both anxiety and caution on discomfort was observed, which encouraged the authors to expect a similar relationship pattern between these 3 dimensions and treatment duration. However, limitations were more strongly related to discomfort than to the other variables. This probably impacted the shape of relationship between treatment duration and discomfort, resulting in the lack of significant relationship between them. The presented results are very similar to those obtained in a previous study by the authors, which also showed that in adolescents with HVA, discomfort was significantly related to caution and limitations, but not to anxiety [16]. Due to limitations of the previously used measurement tool, and the fact that the study had only been conducted among adolescents, these results are not fully comparable $[13,14]$.

It was found that the level of support received by a HVA child increased along with increasing caution and discomfort of the child. This suggests that support acts as a buffer which allows the child to regard its cautious behaviours as a means to ensure a higher level of safety, rather than as personally-felt troublesome restrictions. The results showed that the support received decreased along with treatment duration, being significantly lower in children treated for more than 3 years than in those just being diagnosed. This relationship may be explained by the fact that a long-lasting treatment should provide children with so high tolerance of insect stings, and with so much knowledge and experience concerning their allergy that they are able to deal independently with most of the problems this allergy may cause in their everyday life. The presented results also show that the level of safety decreased as anxiety levels went up, which is an expected result. The results obtained are not comparable with studies on HRQoL of adult patients with HVA. They were also addressed to anxiety, caution and discomfort, but the tool which was applied was interpreted as uni-dimensional [20-28].

Limitations of the study. The main limitation of the study is a lack of children in the study sample with a completed 3-5 years VIT, which is why the level of HRQoL could not be estimated in the children who completed treatment. Moreover, the presented sample did not include children treated with protocols other than ultra rush, therefore the generalization of the obtained results may also be limited. As this study is cross-sectional, conclusions concerning the relationship between the stage of treatment and HRQoL of children should also be treated with some caution. It should be also noted that the model of the study could invoke the use of structural equation modelling (SEM) to test the relationships between all studied variables simultaneously. However, SEM requires a much larger sample sizes than gathered for this study, and should at least exceed 200, which would also result in a higher power of the study [29]. In the case of rare diseases like HVA, it would be very time consuming, as yearly $10-15$ children would be included. This, however, could lead to an oversampling of children staying at diagnostics, in comparison to a proportionally small representation of patients at different stages of treatment. In this study, we did not ask directly for the fact of being stung within the period of VIT treatment. In the case of a mild reaction to a subsequent sting, QoL might be improved.

\section{CONCLUSIONS}

The longest VIT duration is related to lower anxiety, lower caution and lower support received from parents. Anxiety is a dimension of HRQoL which influences the level of all other dimensions of HRQoL, except received support. The limitations depend on both the kind of stinging insect and the place of residence. The greater level of discomfort is related to greater caution and limitations. Children with a higher stage of reaction received a higher level of support. Support received increased along with the child's caution and discomfort. The feeling of safety was higher in children living in villages.

\section{Conflict of interests}

The authors declare that they have no conflict of interests.

\section{Acknowledgements}

The authors express their thanks to Matylda Gawor for critical review of the text as the English proofreader. 


\section{REFERENCES}

1. Carr A, Higginson I, Robinson P. Quality of life. London, BMJ, 2003.

2. Worm M, Francuzik W, Renaudin JM, Bilo MB, Cardona V, Scherer Hofmeier K, et al. Factors increasing the risk for a severe reaction in anaphylaxis: An analysis of data from The European Anaphylaxis Registry. Allergy. 2018; doi: 10.1111/all.13380.

3. Biló BM, Rueff F, Mosbech H, Bonifazi F, Oude-Elberink JNG, the EAACI Interest Group on Insect Venom Hypersensitivity. Diagnosis of Hymenoptera venom allergy. Allergy. 2005; 12: 1339-1349.

4. Cichocka-Jarosz E, Brzyski P, Tobiasz-Adamczyk B, Lis G, Pietrzyk JJ. Development of Children's Hymenoptera Venom Allergy Quality of Life Scale (CHVAQoLS). Clin Translational Allergy. 2013; 3: 25.

5. Taminskiene V, Vaitkaitiene E, Valiulis A, Turner S, Hadjipanayis A, Stukas R, et al. The self-reported quality of life of Lithuanian children with asthma was comparable to Western populations. Acta Paediatr. 2018; 107: 333-338.

6. Silny W, Bartoszak L, Jenerowicz D, Żukiewicz-Sobczak W, Goździewska M. Prevalence of contact allergy in children suffering from atopic dermatitis, seborrhoeic dermatitis and in healthy controls. Ann Agric Environ Med. 2013; 20: 55-60.

7. Yamaguchi C, Futamura M, Chamlin SL, Ohya Y, Asano M. Development of a Japanese Culturally Modified Version of the Childhood Atopic Dermatitis Impact Scale (JCMV-CADIS). Allergol Int. 2016; 65: 312-319.

8. La Grutta S, Landi M, Braido F, Montalbano L, Ferrante G, Malizia V, et al. RHINASTHMA-Adolescents: a new quality of life tool for patients with respiratory allergy. Pediatr Allergy Immunol. 2014; 25: 450-455.

9. Kłak A, Mińko M, Siwczyńska D, Samoliński B. Selected questionnaire methods studying the quality of life. Adv Dermatology Allergol. 2015; 3: $210-215$

10. Storch EA, Small BJ, McGuire JF, Murphy TK, Wilhelm S, Geller DA. Quality of Life in Children and Youth with Obsessive-Compulsive Disorder. J Child Adolesc Psychopharmacol. 2018; 28: 104-110.

11. Boyle RJ, Elremeli M, Hockenhull J, Cherry MG, Bulsara MK, Daniels $\mathrm{M}$, et al. Venom immunotherapy for preventing allergic reactions to insect stings. The Cochrane database of Systematic Reviews. 2012; doi: 10.1002/14651858.CD008838.pub2.

12. Cichocka-Jarosz E, Brzyski P. Children's Hymenoptera Venom Allergy Quality of Life Scale (CHVAQoLS) official webpage. http://www. chvaqols.cm-uj.krakow.pl. (access: 2015.01.05).

13. Brzyski P, Cichocka-Jarosz E, Tobiasz-Adamczyk B, Lis G, JedynakWąsowicz U, Pietrzyk JJ, et al. Adaptacja kwestionariuszy jakości życia dla dzieci z alergią na jad owadów oraz dla ich rodziców [Adaptation of Vespide Allergy Quality of Life Questionnaire for Polish children with venom allergy and for their parents]. Przegl Lek. 2010; 12: 1237-1242.

14. Brzyski P, Cichocka-Jarosz E, Tobiasz-Adamczyk B, Lange J, Świebocka E, Lis G, et al. Theoretical validity and reliability of Vespide Quality of Life Questionnaire in Polish adolescents with Hymenoptera venom allergy. Adv Dermatology Allergol. 2012; 1: 8-13.

15. Tobiasz-Adamczyk B, Brzyski P, Cichocka-Jarosz E. Jakość życia chorych z alergią na jad owadów [Quality of life of patients with venom allergy]. In: Nittner-Marszalska M, editor. Alergia na owady [Insect allergy]. Łódź, Mediton Oficyna Wydawnicza, 2016. p. 105-123.

16. Cichocka-Jarosz E, Brzyski P, Świebocka E, Lange J, Tobiasz-Adamczyk B, Lis G, et al. Health-related quality of life in Polish adolescents with
Hymenoptera venom allergy treated with venom immunotherapy. Arch Med Sci. 2012; 6: 1076-1082.

17. Cichocka-Jarosz E, Tobiasz-Adamczyk B, Brzyski P, Lis G, JedynakWąsowicz U, Pietrzyk JJ, et al. Jakość życia warunkowana stanem zdrowia dzieci z alergią na jad owadów błonkoskrzydłych leczonych VIT oraz jakość życia ich rodziców [Health-related quality of life in children with Hymenoptera venom allergy treated with VIT and quality of life of their parents]. Przegl Lek 2010; 12: 1243-1248.

18. Jaworowska A. Inwentarz stanu i cechy lęku dla dzieci STAIC C.D. Spielbergera, C.D. Edwardsa, R.E. Lyushene'a, J. Montuoriego i D. Platzek [State and trait anxiety inventory STAIC by C.D. Spielberger, C.D. Edwards, R.E. Lyushene, J. Montuori and D. Platzek]. Warszawa, Pracownia Testów Psychologicznych Polskiego Towarzystwa Psychologicznego, 2005.

19. Studenski R. Ryzyko i ryzykowanie [Risk and Risk taking]. Katowice, Wydawnictwo Uniwersytetu Śląskiego, 2004.

20. Oude-Elberink JNG, de Konchy JGR, Golden DBK, Brouwer J-LP, Guyatt GH, Dubois AEJ, et al. Development and validation of a healthrelated quality-of-life questionnaire in patients with yellow jacket allergy. J Allergy Clin Immunol. 2002; 1: 162-170.

21. Oude Elberink JNG, Dubois AEJ. Quality of life in insect venom allergic patients. Curr Opin Allergy Clin Immunol. 2003; 3: 287-293.

22. Niedoszytko M, Majkowicz M, Chełmińska M, Buss T, GruchałaNiedoszytko M, Jassem E. Quality of life, anxiety, depression and satisfaction with life in patients treated with insect venom immunotherapy. Adv Dermatology Allergol. 2012; 2: 74-79.

23. Fischer J, Feidt A, Giel KE, Martens U, Zipfel S, Biedermann T, Teufel M. Quality-of-life in wasp venom allergy - validation of the German version of the "Vespid Allergy Quality of Life Questionnaire"(VQLQ-d). JDDG; 2011; 9: 379-385.

24. Koschel DS, Schmies M, Nink Weber C, Höffken G, Balck F. Tolerated Sting Challenge in Patients on Hymenoptera Venom Immunotherapy Improves Health-Related Quality of Life, J Investig Allergol Clin Immunol. 2014; 24: 226-230.

25. Alfaya T, Vega A, Domínguez-Noche C, Ruiz B, Marqués L, SánchezMorillas L. Longitudinal Validation of the Spanish Version of the Health-Related Quality of Life Questionnaire for Hymenoptera Venom Allergy (HRQLHA). J Investig Allergol Clin Immunol. 2015; 25: 426-430.

26. Armisén M, Guspi R, Alfaya T, Cruz S, Fernández S, DomínguezNoche C, Alonso A, Dalmau G, Marqués L, Vega A. Cross-Sectional Validation of a Quality of Life Questionnaire in Spanish for Patients Allergic to Hymenoptera Venom. J Investig Allergol Clin Immunol. 2015; 25 : 107-111.

27. Sin BA, Öztuna D, Gelincik A, Gürlek F, Baysan A, Sin AZ, Aydın Ö, Misırlıgil Z. Quality-of-life in insect venom allergy: validation of the Turkish version of the "Vespid Allergy Quality of Life Questionnaire"(VQLQ-T), SpringerPlus 2016; 5: 583, DOI 10.1186/ s40064-016-2246-x.

28. Silva D, Pereira AM, Santo SN, Amaral L, Delgado L, Oude Elberink J.N.G. (H.), Coimbra A. The Vespid Allergy Quality of Life Questionnaire - cultural adaptation and translation to Portuguese. Eur Ann Allergy Clin Immunol. 2017; 49: 114-121.

29. Schumacker RE, Lomax RG. A beginner's guide to structural equation modelling, Second edition. Mhawah: Lawrence Erlbaum Associates 2004. 